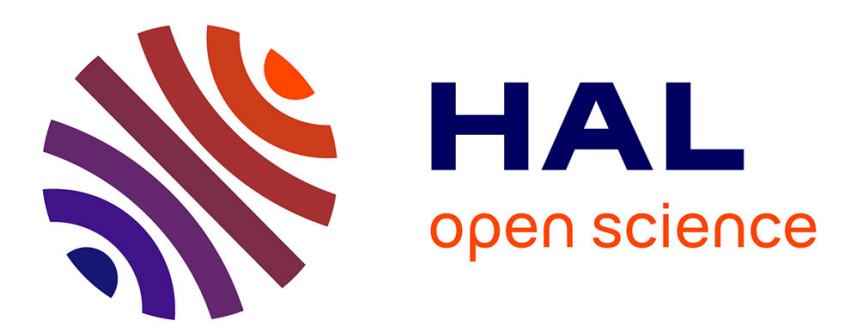

\title{
Characterization of grain boundary misorientations in a alumina by large angle convergent beam electron diffraction
}

\author{
J. Morniroli, A. Leclere, W. Swiatnicki, J. Laval
}

\section{To cite this version:}

J. Morniroli, A. Leclere, W. Swiatnicki, J. Laval. Characterization of grain boundary misorientations in a alumina by large angle convergent beam electron diffraction. Journal de Physique IV Proceedings, 1993, 03 (C7), pp.C7-1455-C7-1458. 10.1051/jp4:19937226 . jpa-00251862

\section{HAL Id: jpa-00251862 https://hal.science/jpa-00251862}

Submitted on 1 Jan 1993

HAL is a multi-disciplinary open access archive for the deposit and dissemination of scientific research documents, whether they are published or not. The documents may come from teaching and research institutions in France or abroad, or from public or private research centers.
L'archive ouverte pluridisciplinaire HAL, est destinée au dépôt et à la diffusion de documents scientifiques de niveau recherche, publiés ou non, émanant des établissements d'enseignement et de recherche français ou étrangers, des laboratoires publics ou privés. 


\title{
Characterization of grain boundary misorientations in $\alpha$ alumina by large angle convergent beam electron diffraction
}

\author{
J.P. MORNIROLI, A. LECLERE, W. SWIATNICKI ${ }^{*}$ and J.Y. LAVAL*
}

Laboratoire de Métallurgie Physique, Associé CNRS URA 234, Université de Lille I, Bât C6, 59655 Villeneuve d'Ascq cedex, France

* Laboratoire de Physique du Solide, UPR5 CNRS, ESPCI Paris, 10 rue Vauquelin, 75231 Paris cedex 05, France

\begin{abstract}
Large Angle Convergent Beam Electron Diffraction (LACBED) is used in order to characterize accurately the misorientation between grains situated on each side of grain boundaries in $\alpha$ alumina. It is shown that this method leads to an improved accuracy for the determination of misorientations between crystals at interfaces, when compared with the traditional diffraction and Kikuchi line techniques.
\end{abstract}

I. DESCRIPTION OF THE LACBED TECHNIQUE

LACBED is a variant of Convergent Beam Electron Diffraction (CBED). It allows the convergence angle limitation due to the overlapping of the transmitted and diffracted disks which occurs in a CBED pattern to be overcome.

In the LACBED technique, an incident electron beam with a convergence semi-angle of about $3^{\circ}$ is focused on the object plane and the specimen is raised from its normal position by $\Delta h$. This modification produces two main effects:

The first effect is to separate, in the object and image planes, the transmitted and diffracted beams, as shown in Fig. 1. Consequently, the transmitted beams can be isolated from the diffracted ones by means of the selected area diffraction aperture. A bright field LACBED pattern is then observed in the objective back focal plane.

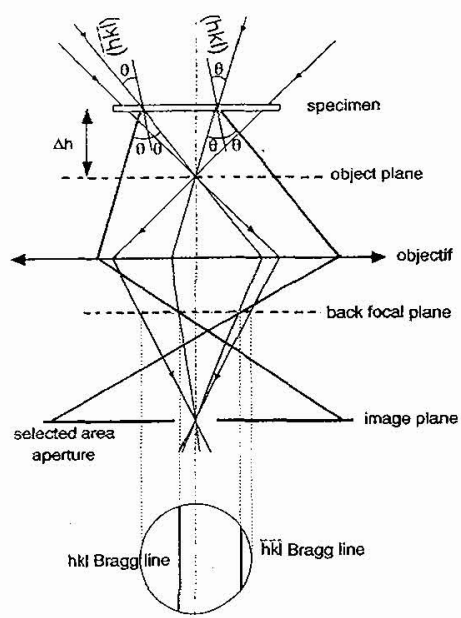

Figure 1. LACBED Ray-paths

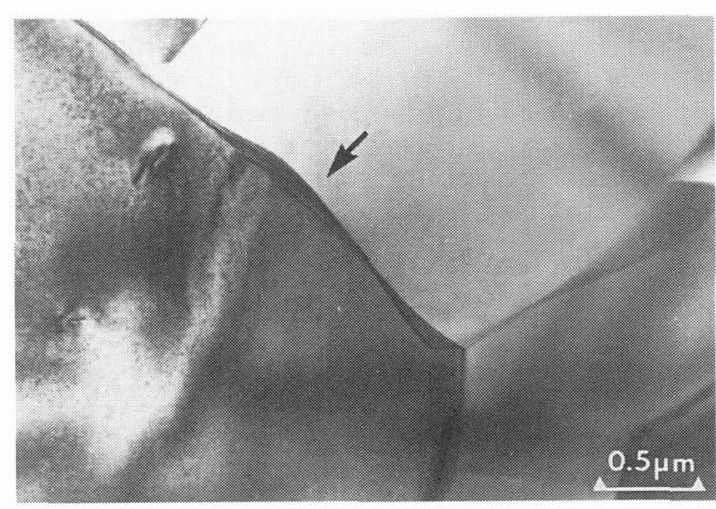

Figure 2. Electron micrograph of the studied grain boundary 
This is composed of deficiency dark lines called Bragg lines or Bragg contours which represent the specimen loci that are in exact Bragg position.

The second effect concerns the direct space. Since the specimen is not situated exactly in the object plane, its shadow image is simultaneously observed in the LACBED pattern. As a result, a LACBED pattern contains both direct and reciprocal features.

Among these features, Bragg lines with high hkl indices are of particular interest. Owing to their long extinction distance, they exhibit nearly kinematical behaviour and consequently appear as sharp dark lines. These lines can be used to identify with great accuracy the orientation of a specimen with respect to the electron beam.

\section{EXPERIMENTAL METHODS}

The $\alpha \mathrm{Al}_{2} \mathrm{O}_{3}$ specimens are composed of crystals with an average size of about $2 \mu \mathrm{m}$. The grain boundary examined in this study is shown in Fig. 2 .

Thin foils, prepared by ion milling, are observed with a Philips CM30 electron microscope working at $300 \mathrm{kV}$ in the nanoprobe mode with a spot size of about $20 \mathrm{~nm}$ and a $3^{\circ}$ electron beam semi-convergence.

\section{EXPERIMENTAL RESULTS}

A first LACBED pattern is produced with the grain boundary located near its centre (Figure 3b). On each side of the grain boundary, such a pattern exhibits Bragg lines typical of the orientation of each grain (grains I and II). To obtain this pattern, the specimen is orientated with respect to the electron beam, so that most of these Bragg lines are sharp (orientation A). Usually, convenient patterns are obtained for orientations which are not close to a high symmetry zone axis. It is also recommended that a specimen orientation is considered, in which the grain boundary is nearly parallel to the electron beam as this reduces the specimen area where the two grains are superimposed. This area gives a complex LACBED pattern, largely since the thickness of each of the two crystals changes in this area while their total thickness remains constant.

So as to enable an interpretation, two other LACBED patterns are recorded from grains I and II, which may be isolated by moving the grain boundary (Fig. $3 a$ and $\mathrm{C}$ ).

The next step consists of identifying the Bragg lines for each of the two grains. This stage is performed by comparing the experimental LACBED pattern with theoretical ones. By means of a computer program based on the kinematical theory and specially developped for this application, the theoretical patterns of Fig. 3d, e and $f$ are obtained. These are in perfect agreement with the experimental patterns.

Two main problems may be encountered during this operation:

- since a LACBED pattern only covers a very small angular domain (about $6^{\circ}$ ), it can be very tedious to identify this domain from comparisons with theoretical patterns. One solution we use consists of tilting the specimen until a known zone axis is reached, thus giving a rough localisation.

- very often the specimen is somewhat buckled. As a result, the LACBED pattern may be strongly distorted and comparison with theoretical patterns becomes nearly impossible. To overcome this difficulty, the specimen should be lower back to its normal position in the object plane in order to obtain a true CBED pattern. The convergence angle can also be reduced in order to suppress disk superimpositions. The resulting pattern is not distorted and can be easily identified. 

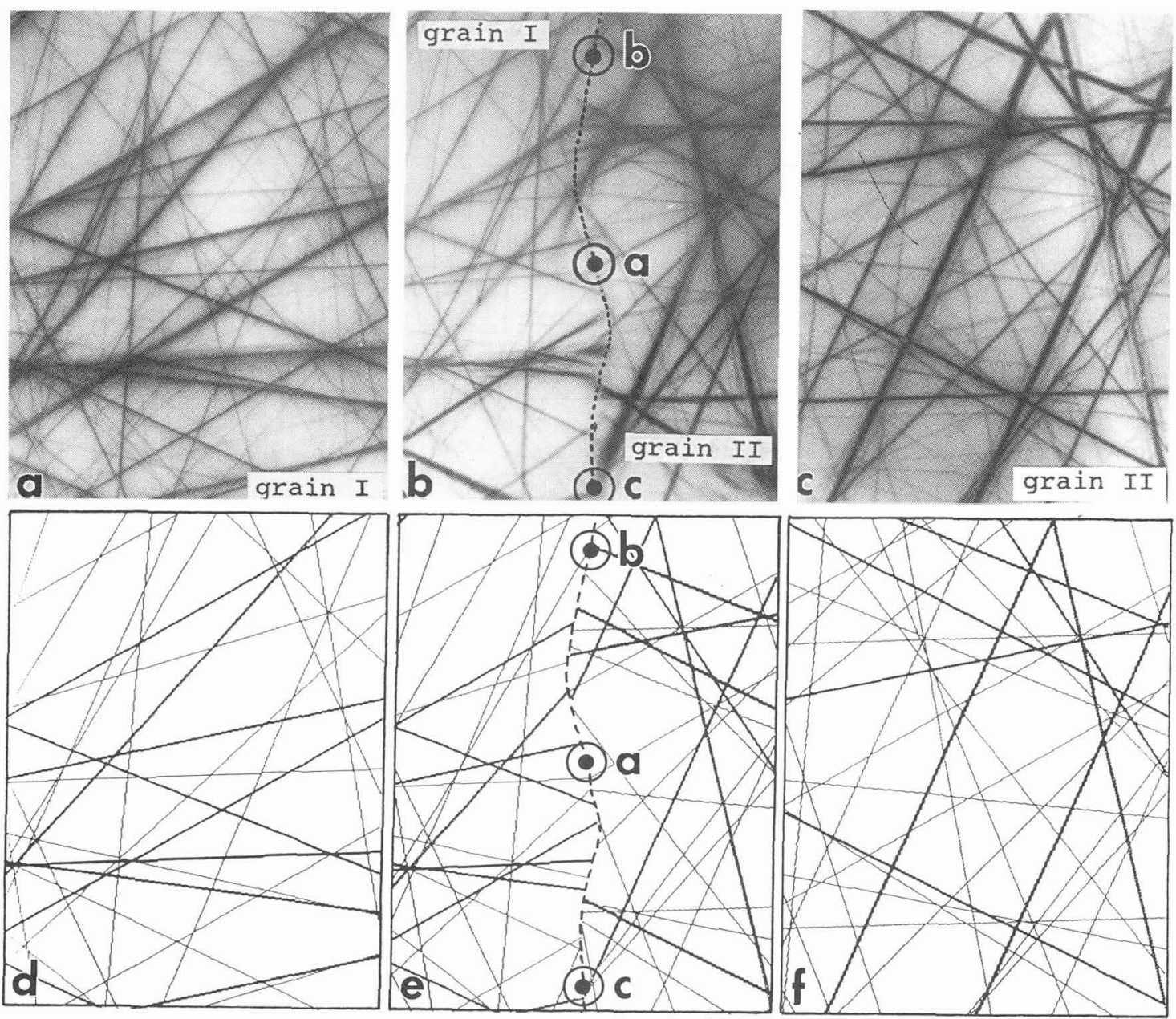

Figure 3. Experimental and theoretical LACBED patterns obtained on the grain boundary ( $b$ and $e$ ), on grain $I$ ( $a$ and $d$ ) and on grain II (c and $f$ ) for orientation $A$.
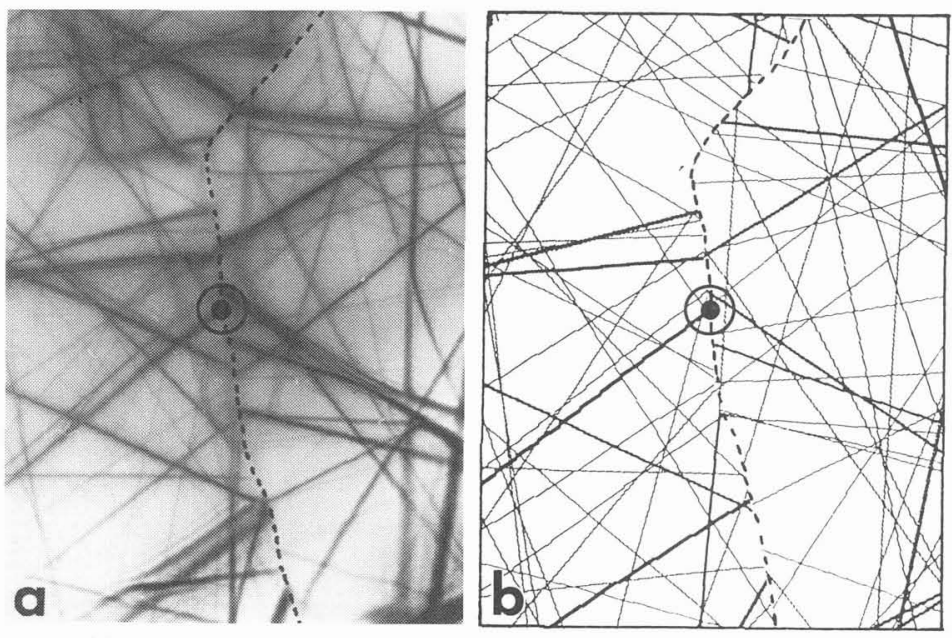

Figure 4.

Experimental and theoretical LACBED patterns obtained on the grain boundary for orientation B. 
- Each point on a LACBED pattern corresponds to a definite grain orientation and this orientation can be identified by means of the program described above.

- Each point on a LACBED pattern comes from an elementary beam having a definite orientation in the incident electron beam.

Therefore, if we consider a point located on the grain boundary (or very close to it), this is common to both grains and it corresponds to the orientations [uvw] IA for grain $I$ and [uvw]IIA for grain II. These directions are strictly parallel since they are both due to the same elementary incident electron beam, which acts as a reference direction. A point located on the grain boundary also ensures the elimination of any artefact connected with accidental misorientations or with thin foil relaxation.

Using this method, for the common point (a) shown in Fig.3b and e, the two following grain orientations are obtained:

$\left[\mathrm{UVW}_{\mathrm{IA}}=\left[\begin{array}{lll}-2091 & -192 & 235\end{array}\right]\right.$ and $[\mathrm{UVW}] \mathrm{IIA}_{\mathrm{A}}=\left[\begin{array}{lll}2326 & 1249 & -218\end{array}\right]$.

A second experiment is then performed with an orientation of the grain boundary with respect to the electron beam that is far from the first one (orientation B). The pattern produced (Fig. $4 \mathrm{a}$ and b) is interpreted in the same way as above, giving:

$$
\left[\mathrm{UVW} \text { ] IB }=\left[\begin{array}{lll}
-2125 & -1964 & 173
\end{array}\right] \text { and [uVW] IIB }=\left[\begin{array}{lll}
1016 & 168 & -688
\end{array}\right] .\right.
$$

It is necessary that this second couple of orientations is coherent with the first one. Therefore, the tilt angles which permit transition from orientation $A$ to orientation $B$ should be taken into account for this analysis.

From the two series of experiments performed, the following rotation matrix [R], rotation direction $[\mathrm{UVW}] \mathrm{R}$ and rotation angle $\theta \mathrm{R}$ are inferred:

$\begin{array}{llll}0.041 & 0.275 & -0.334\end{array}$

$$
[R]=\left|\begin{array}{ccc}
-1.115 & 0.740 & 0.570 \\
-0.327 & 0.516 & 2.813 \\
0.041 & 0.275 & -0.334 \\
\text { tast features } & \text { fully }
\end{array}\right|
$$

$\left[\mathrm{UVW}\right.$ ] R $=\left[\begin{array}{lll}3870 & 9460 & 2075\end{array}\right]$

$\theta_{\mathrm{R}}=165.14^{\circ} \pm 0.05^{\circ}$

These two last
misorientation.

characterize the grain boundary

Note: Two common points selected on the grain boundary present in the same LACBED pattern (see for example points (b) and (c) in Fig.3b) correspond to two different orientations of the beam with respect to the grain boundary. These can also be used to deduce the misorientation. In this case the accuracy obtained is inferior but the use of a unique LACBED pattern constitutes a significant experimental simplification.

\section{$\mathrm{V}$ CONCLUSIONS}

The main advantage of this method by comparison with the traditional techniques involving diffraction and Kikuchi lines is the superior accuracy which can be obtained, (estimated to be $\pm 0.05^{\circ}$ ). In addition, it is also possible to deduce the misorientation from a unique LACBED pattern.

The grain boundary orientation can also be obtained from the LACBED pattern because both the diffraction pattern and the image are simultaneously present without any rotation between them. LACBED also has important potential applications in the analysis of coincidence grain boundary, rigid body shift, grain boundary dislocations.

The method can be applied to many types of specimen (ceramics, semiconductors, metals) provided the grain size is about $0.3 \mu \mathrm{m}$. 